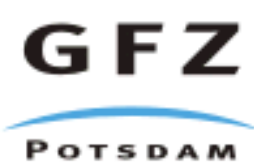

Originally published as:

Mandea, M., Korte, M., Mozzoni, D., Kotzé, P. (2007): The magnetic field changing over the southern African continent: a unique behaviour. - South African Journal of Geology, 110, 2-3, 193-202

DOI: 10.2113/gssajg.110.2-3.193 


\title{
The magnetic field changing over the southern African continent: a unique behaviour
}

\author{
Mioara Mandea, Monika Korte and David Mozzoni \\ GeoForschungsZentrum Potsdam, Telegrafenberg, Potsdam, Germany \\ e-mail: mioara@gfz-potsdam.de; monika@gfz-potsdam.de; dmozzoni@gfz-potsdam.de;
}

\author{
Pieter Kotzé \\ Hermanus Magnetic Observatory, South Africa. \\ e-mail: pkotze@hmo.ac.za
}

(c) 2007 September Geological Society of South Africa

\begin{abstract}
High-quality magnetic observations have been obtained in recent years from a number of satellite missions. The satellite-based magnetic data, combined with ground-based data (observatory and repeat station measurements), have provided unique opportunities for studying the magnetic field of the Earth's core and its secular variation over the globe. The southern African continent (extending into the southern Atlantic Ocean) is an important area for such studies because of its intriguing field behaviour at both the Earth's surface and at the core-mantle boundary. A few examples of recent improvements in our knowledge of the core's magnetic field and its secular variation over this specific region are presented, together with future developments in this zone.
\end{abstract}

\section{Introduction}

The main part of the Earth's magnetic field is due to a geodynamo mechanism in the liquid, metallic, outer core, and is known as the main field or core field. To this dominant contribution of the Earth's magnetic field one must consider the lithospheric field that arises from rocks that formed from the molten state and thus contain information about the magnetic field at the time of their solidification. Another significant contribution is that of external field sources, which originate in the ionosphere and magnetosphere. These variable sources include the daily solar quiet variations, the ring current variations, the contributions from magnetic storms, and many other current systems (e.g., the field-aligned currents, and the auroral and equatorial electrojets). To these different contributions one must add currents induced in the solid Earth by external fields. Measurements of the geomagnetic field at a given time and location provide a composite value of the fields from the different origins. Separating these contributions is not an easy task (e.g. Mandea and Purucker, 2005; Maus and Lühr, 2005; Maus et al., 2006; Olsen et al., 2006; Thomson and Lesur, 2007). However, using a spherical harmonic expansion of the geomagnetic field potential, a separation between internal and external contributions to the field can be obtained. Errors and non-uniform distribution of data can deteriorate results, and this separation becomes more critical in practice.

The geomagnetic field is also subject to temporal variations over various time scales. The so-called shortterm variations are detectable over time scales ranging from $\sim 0.01$ second to decades. The very short period variations (seconds to hours) are usually attributed to the Earth's external sources, while the longer-period variations (annual to decadal) are due to solar cycle variations and harmonics, superposed on the core field temporal variation. The core field temporal variation is known as the secular variation. Important characteristics of secular variation are the changes evident in its trend, which are phenomena occurring on decadal or subdecadal scale and named geomagnetic jerks. These features are not yet completely understood, but may reflect the contribution of hydromagnetic motions in the outer core over small scales. Moreover, these phenomena are difficult to study, because of their small amplitudes and the overlap of their frequency range with the effect of solar-dependent external variations. In addition, the highly uneven coverage of the globe by magnetic observatories also makes their study difficult (e.g. Mandea and Purucker, 2005).

Observations of the full vector magnetic field have existed for more than one century. In addition to the current observatory network (www.intermagnet.org), vector measurements provided by satellites have greatly improved our knowledge of the geomagnetic field all over the globe. However, in the following we only concentrate on the so-called Southern Atlantic Hemisphere (SAH), which we define as being both the South Atlantic and the southern African continent.

During the last few years, huge efforts have been made in measuring and understanding the geomagnetic field behaviour over and under the SAH region, and some of the key questions linked to this topic are addressed below. Our research is part of Inkaba ye Africa, a major initiative of the German and South African earth science communities to understand the Earth's system processes and their interaction at different scales and rates, which has been running now for four years. In the Heart of Africa programme, one interesting 


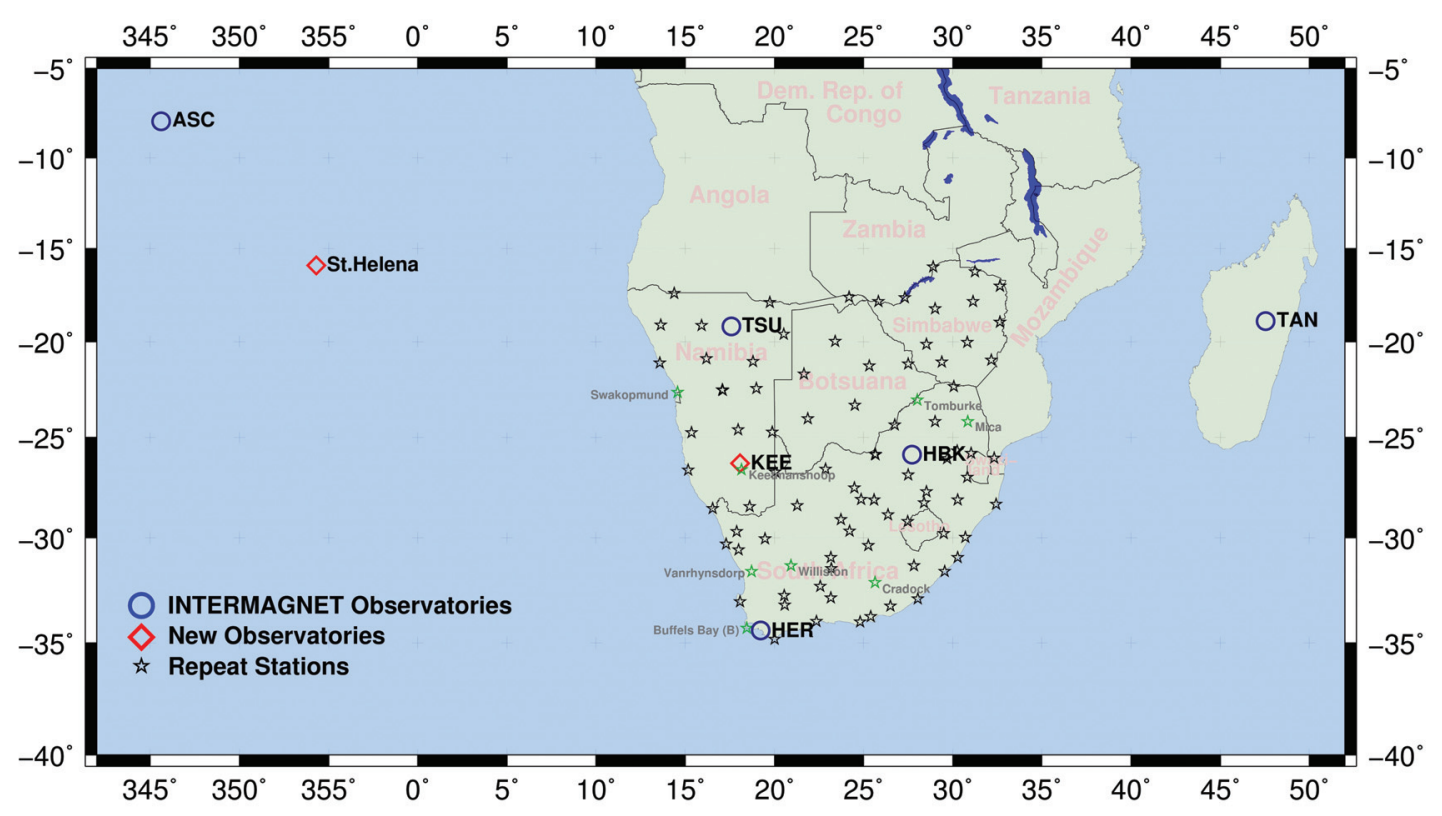

Figure 1. Distribution of magnetic data over the Southern Atlantic Hemisphere (SAH) provided by INTERMAGNET magnetic observatories (circles); new magnetic observatories, installed or planned (diamonds); repeat stations (stars). The named repeat stations are used in Figure 4 .

topic is tracking the behaviour of the geomagnetic field over the southern African region. A project named COMPASS (Comprehensive Magnetic Processes under the African Southern Sub-continent), a study of the geomagnetic field in this region, supported by the global monitoring of the magnetic field from satellites like CHAMP, is helping to better explain and predict the secular variation.

In this paper we firstly present the available data over our region of interest, some of the geomagnetic field particularities in this area, and conclude with proposed measurements and studies to better understand the field behaviour in the SAH.

\section{Geomagnetic data for Southern Atlantic \\ Hemisphere (SAH) \\ Ground-based data}

Observatory data

Modern land-based magnetic observatories use similar instrumentation to produce similar data products. The fundamental measurements recorded are oneminute values of the vector components and scalar intensity; however, a recent INTERMAGNET (www.intermagnet.org) recommendation is to develop and install instruments able to record one-second values. From the one-minute data, hourly, daily, monthly and annual mean values are produced. The monthly and annual mean values are used to determine the secular variation originating inside the Earth's core. For our region of interest, the number of observatories is dramatically reduced (Figure 1), when compared with an equivalent area in either Europe or North America.
The observatory distribution is a key parameter in determining the secular variation. This is the reason why in some regions, like the $\mathrm{SAH}$, the secular variation uncertainty is higher than in better-covered regions such as Europe, where it is a few nT/yr (e.g. Verbanac et al., 2007). Moreover, detailed studies of geomagnetic jerks are not well suited, as the magnetic observatories operating in the area are far apart and present a very different and intriguing behaviour from one site to another (see below).

\section{Repeat station data}

In order to improve the data distribution over this region, the southern African continent repeat station network is taken into account (Figure 1). During the last few decades, efforts have been taken by Hermanus Magnetic Observatory to establish and measure a network of repeat stations, today covering the territories of South Africa, Namibia and Botswana (Kotzé et al., 2007a). During the last two years these stations were reoccupied and measured on a yearly basis in the frame of the COMPASS project. At the time of writing, the repeat station measurements done in 2005 have been processed and the data are available. The 2006 campaign measurements will be available in 2007. For more detail on the survey method, data processing and uncertainty estimates, the reader is requested to consult the paper by Korte et al. (2007b).

\section{Satellite data}

The first satellite that provided valuable vector data was MAGSAT, which supplied magnetic measurements over a six-month period between 1979 and 1980 . 


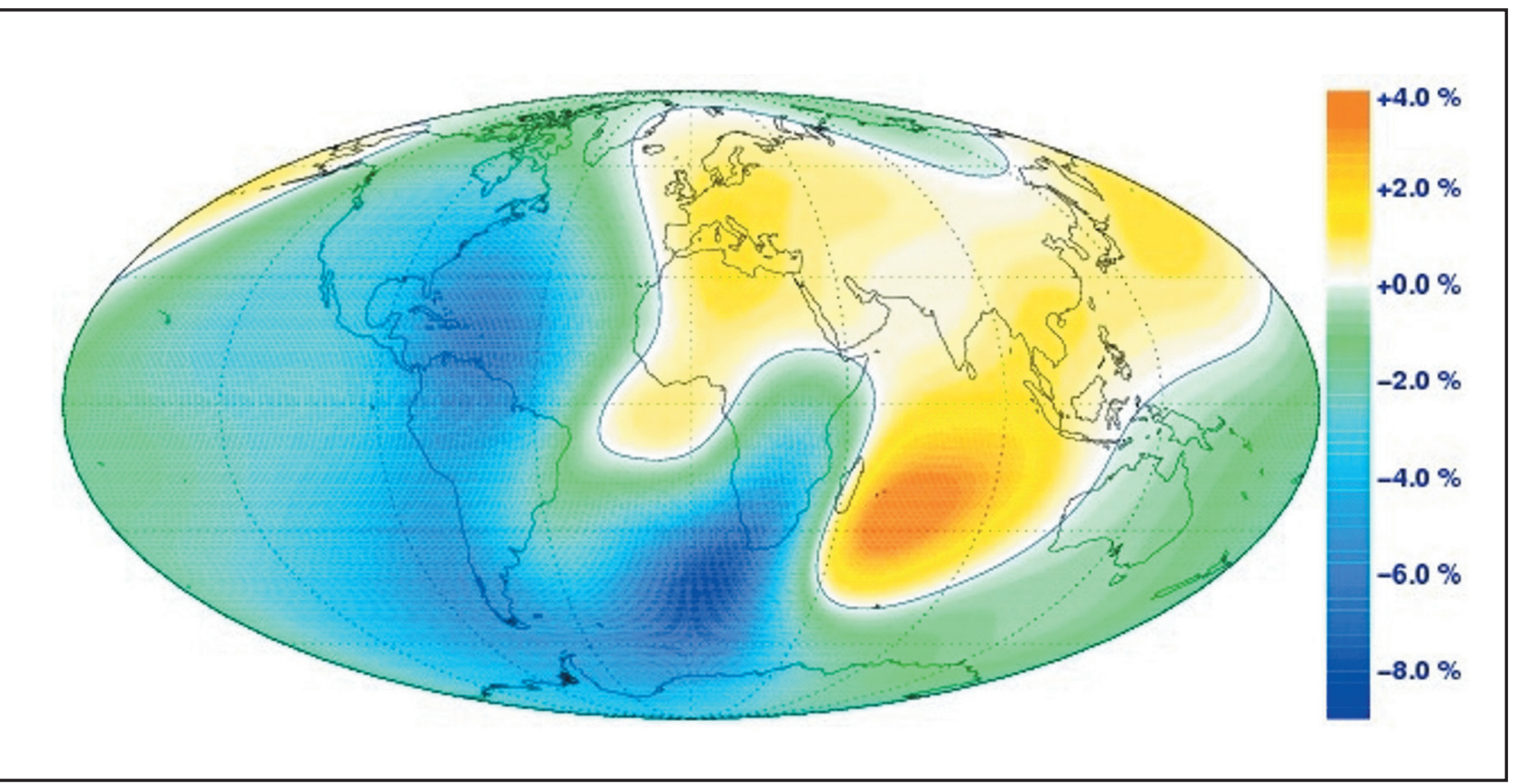

Figure 2. Map of the change in the core magnetic field intensity between the MAGSAT (1980) and CHAMP (2002) epochs.

The following 20 years were without satellite magnetic coverage. However, in recent years, the geomagnetic community has been provided with a wealth of new high-quality data from several near-Earth satellites: Ørsted (www.dmi.dk) (1999 to present), CHAMP

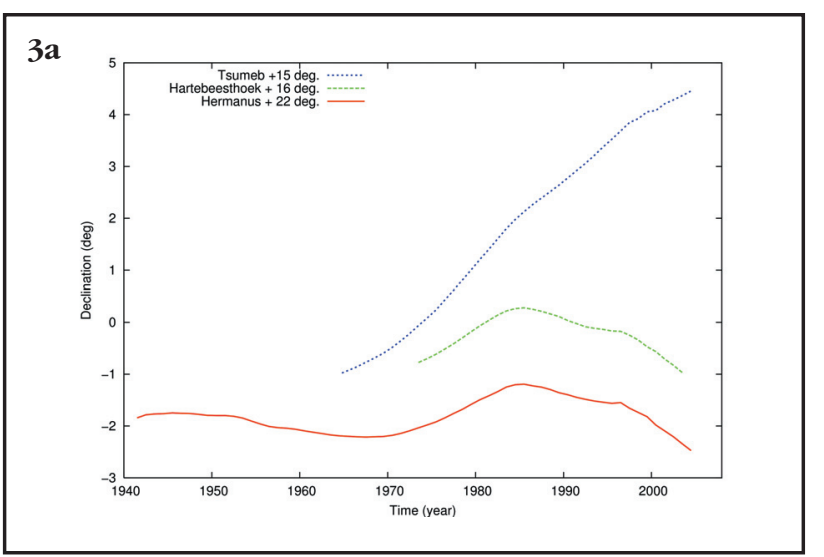

$3 \mathbf{b}$

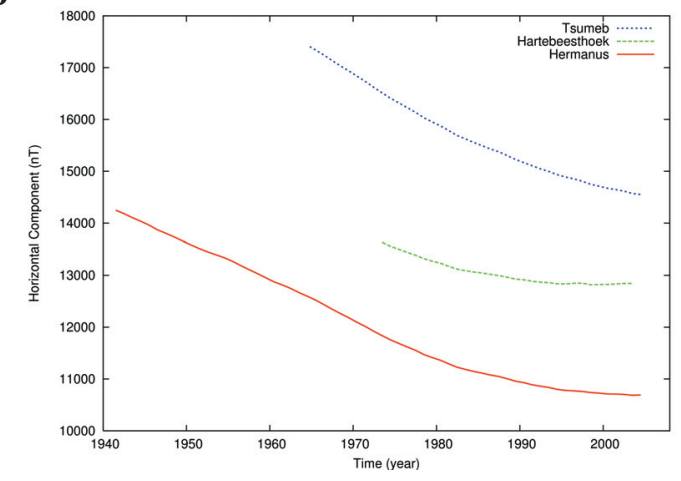

(www.gfz-potsdam.de) (2000 to present) and SAC-C (www.dnsc.dk) (2000 to present). Currently, Ørsted and SAC-C are less useful: Ørsted because of its long time period in space (note that its nominal life was just 14 months), and SAC-C because the vector data cannot be directly used, as the star camera has given no information during the course of the mission. The CHAMP satellite, with its highly precise, multifunctional and complementary payload elements (magnetometer, accelerometer, star sensor, GPS receiver, laser retro reflector, ion-drift meter) and its orbital characteristics (near polar, low altitude, long duration), currently provides high-precision gravity and magnetic field measurements. The almost circular and near-polar orbit $\left(87.3^{\circ}\right.$ with respect to the equator) allows for a homogeneous and almost complete global coverage of the Earth. The CHAMP scalar magnetometer provides an absolute in-flight calibration capability for the vector magnetic field measurements.

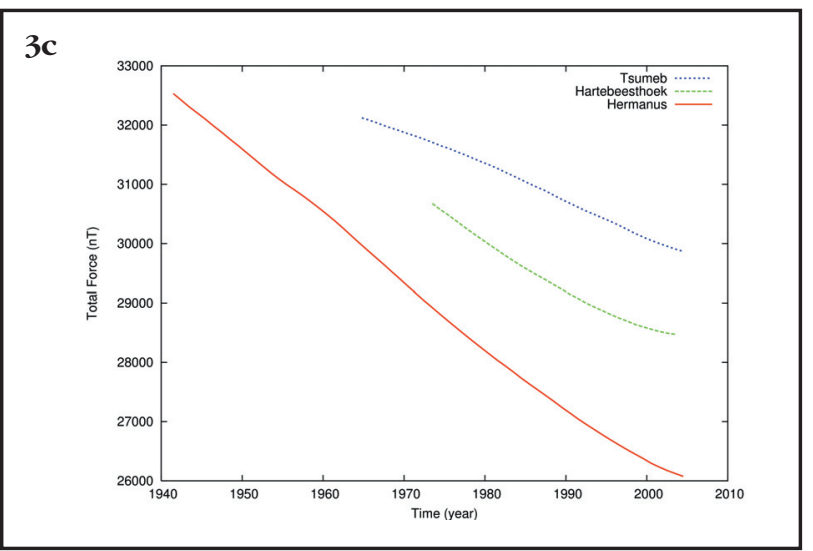

Figure 3. Temporal evolution for the magnetic field components: $D$ (declination) $H$ (horizontal component) and $F$ (total field intensity) for the Hermanus (HER), Hartebeesthoek (HBK) and Tsumeb (TSU) observatories. 
$4 a$

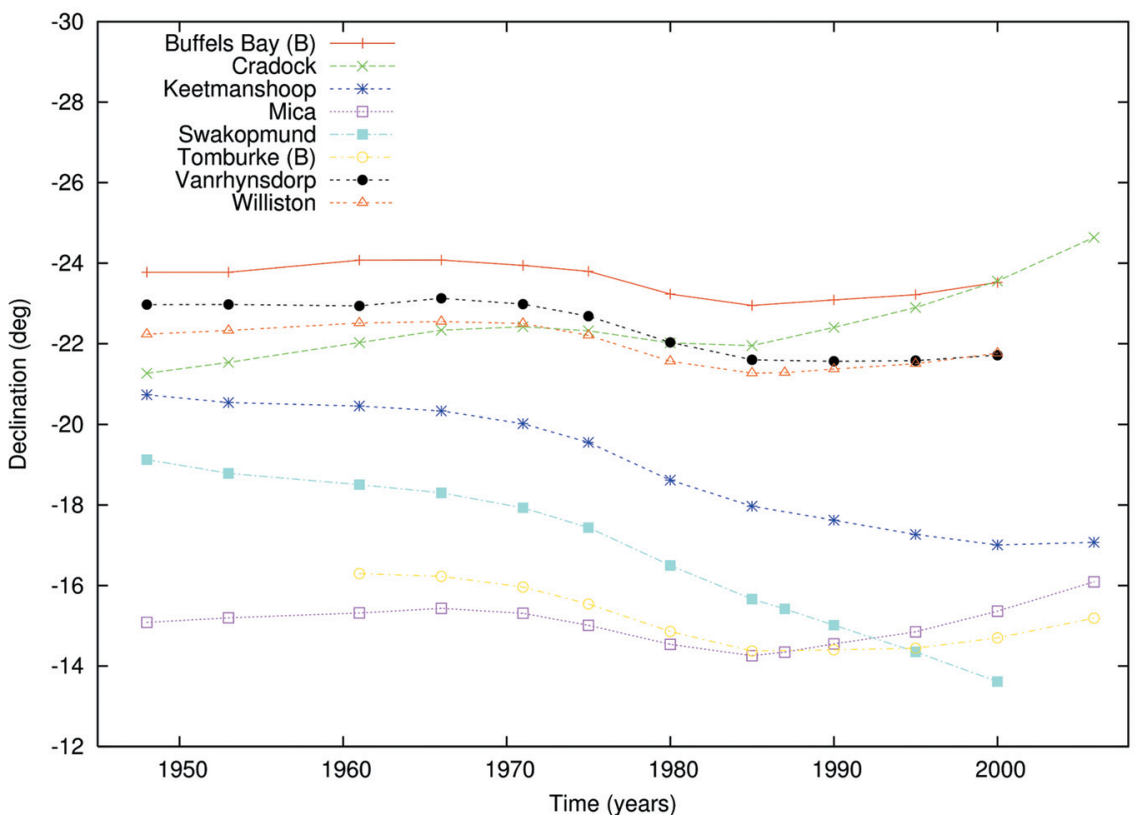

$4 \mathbf{b}$

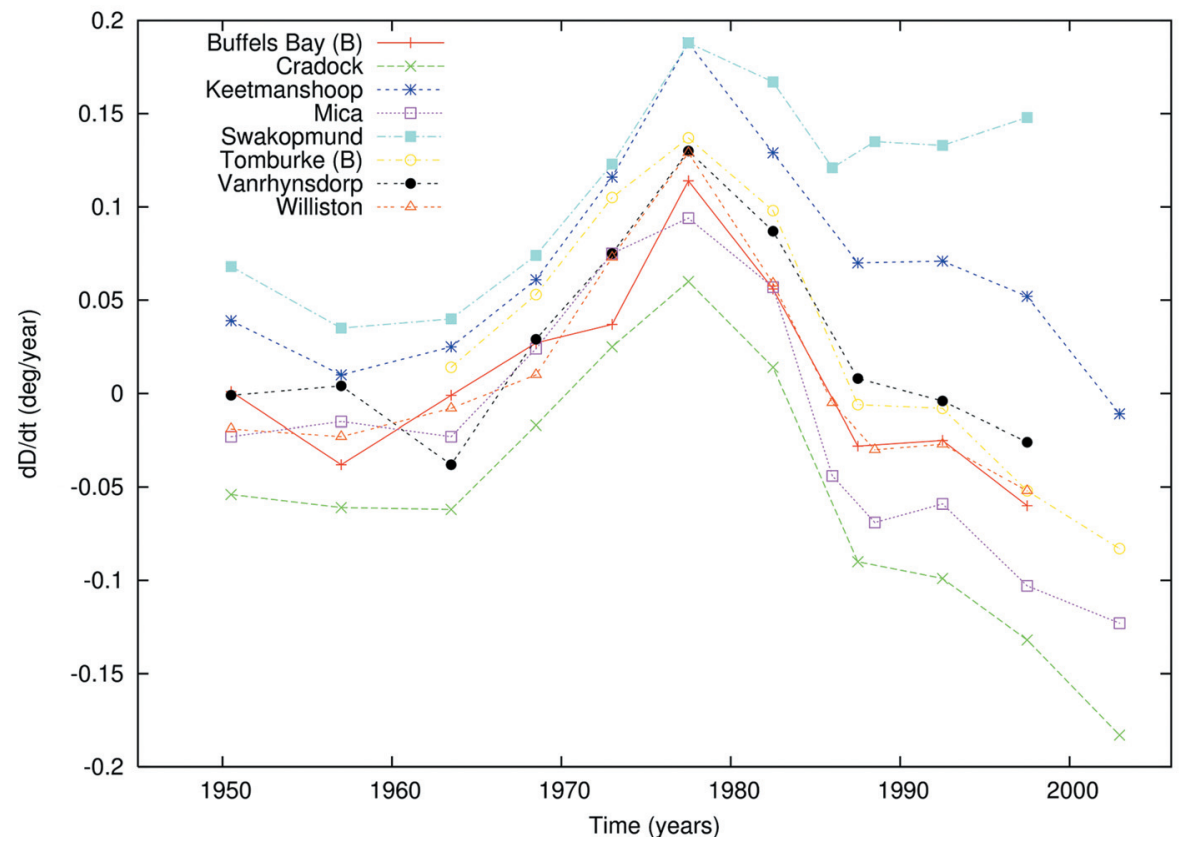

Figure 4 Temporal evolution for the magnetic field components: $D$ (declination) $H$ (horizontal component) and $F$ (total field intensity) and their secular variation for eight repeat stations distributed over the southern African continent (see Figure 1 for their spatial distribution).

These three satellite datasets have been used for computing various models based on satellite data only, or by combining satellite data with ground data. The internal part of the geomagnetic field is generally described mathematically by a spherical harmonic expansion. This is the representation of the magnetic field potential as a series of multipoles: $n=1$ represents the dipole contribution, $n=2$ that from a quadrupole, $n=3$ from octopole and so on. The degrees thus are a measure for spatial wavelength. At smaller degrees the field from the core is dominant. Between approximately degrees $n=13$ and 15 , or 3000 to $2600 \mathrm{~km}$ wavelength, the observed field is strongly influenced by both core and lithospheric field contributions. For degrees larger than $n=15$, the short wavelengths of the core field are masked by the lithospheric signal, and the long 


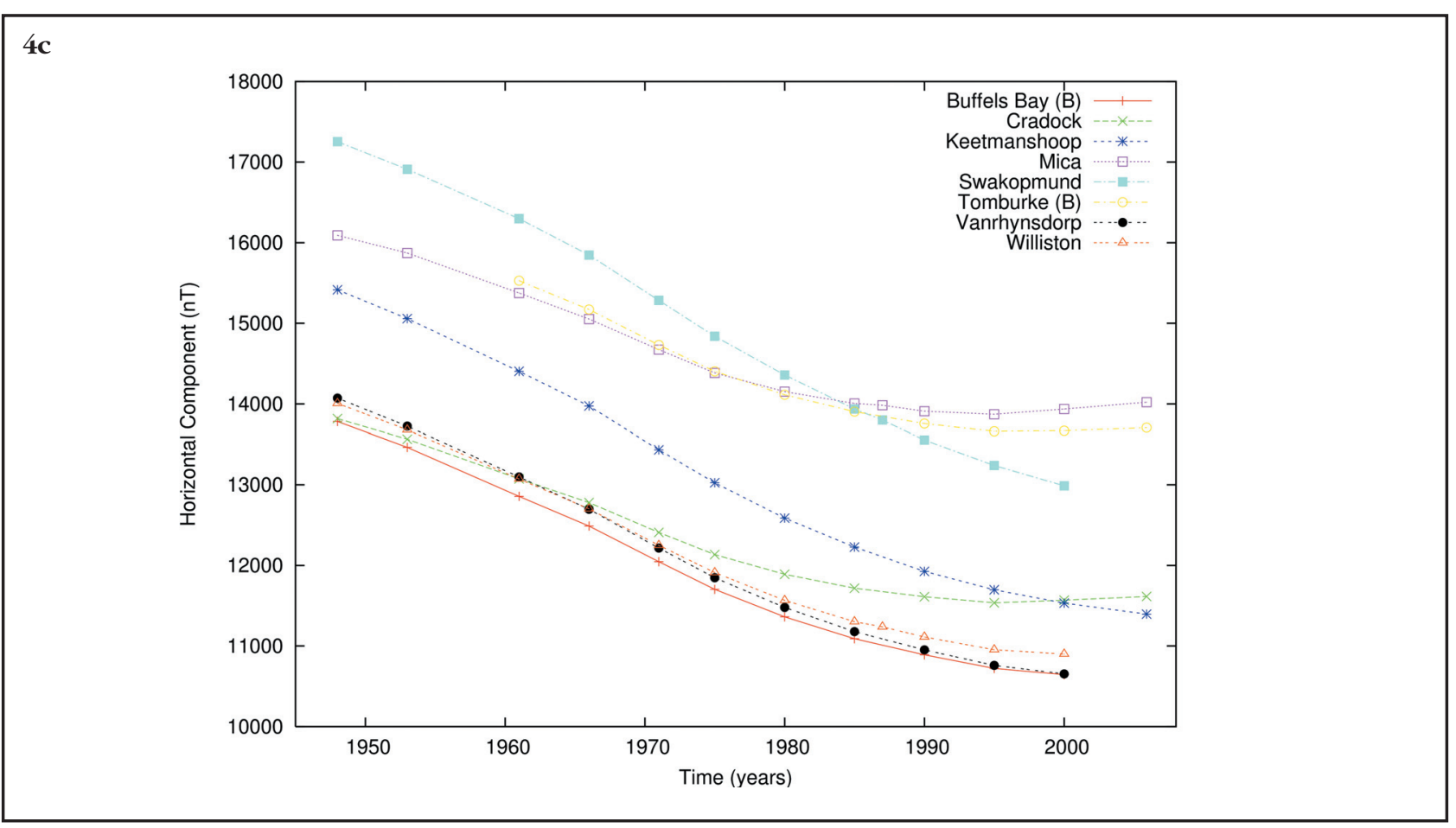

$4 \mathbf{d}$

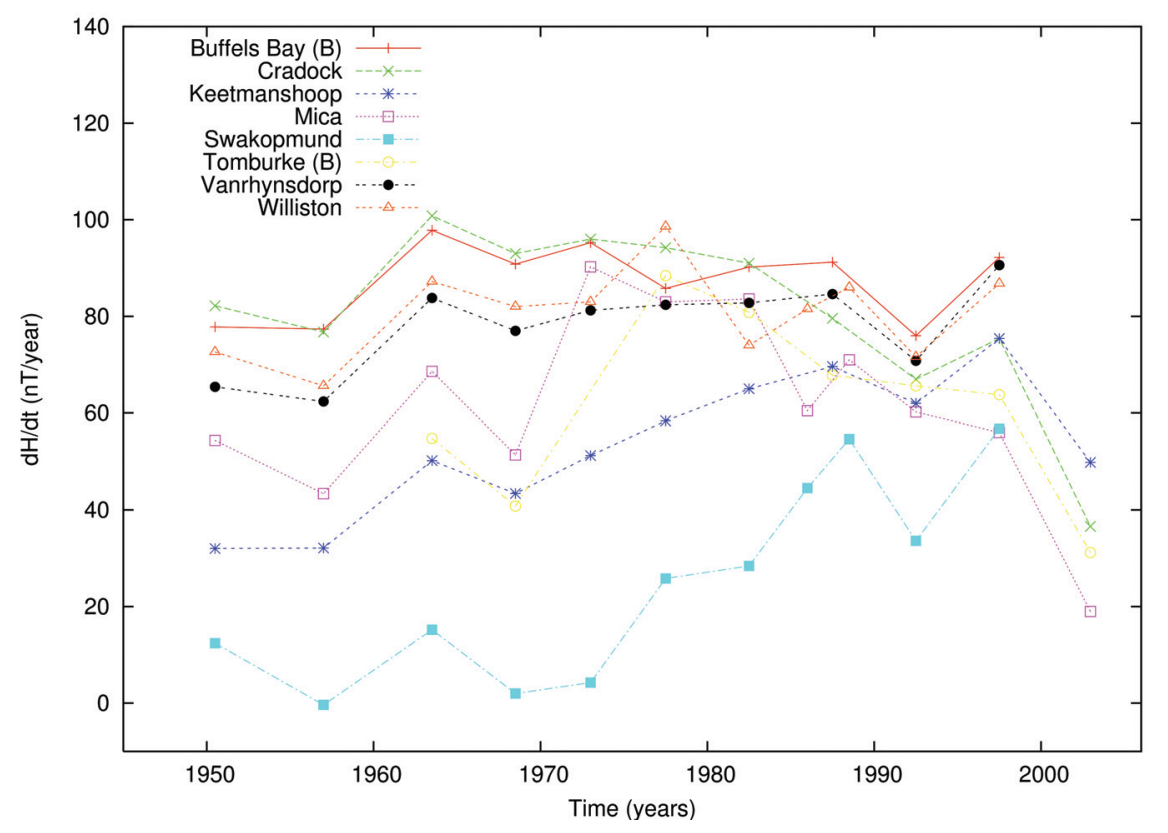

Figure 4 continued. Temporal evolution for the magnetic field components: $D$ (declination) $H$ (horizontal component) and $F$ (total field intensity) and their secular variation for eight repeat stations distributed over the southern African continent (see Figure 1 for their spatial distribution).

wavelength features of the lithospheric field are buried under the large core field amplitudes. Some of these global models, representing both the static field and the secular variation to different degree/order, are used in the following discussions. However, for the regional modelling, information of the main field evolution can be obtained from the ground-stations (Kotzé et al., 2007). Mainly in the southern African continent the repeat station data are very useful for accurately monitoring the secular variation.

Temporal changes of the geomagnetic field at the Earth's surface

\section{Secular variation and geomagnetic jerks}

Modelling of the secular variation (with characteristic time scales of the order of years to decades) can be 

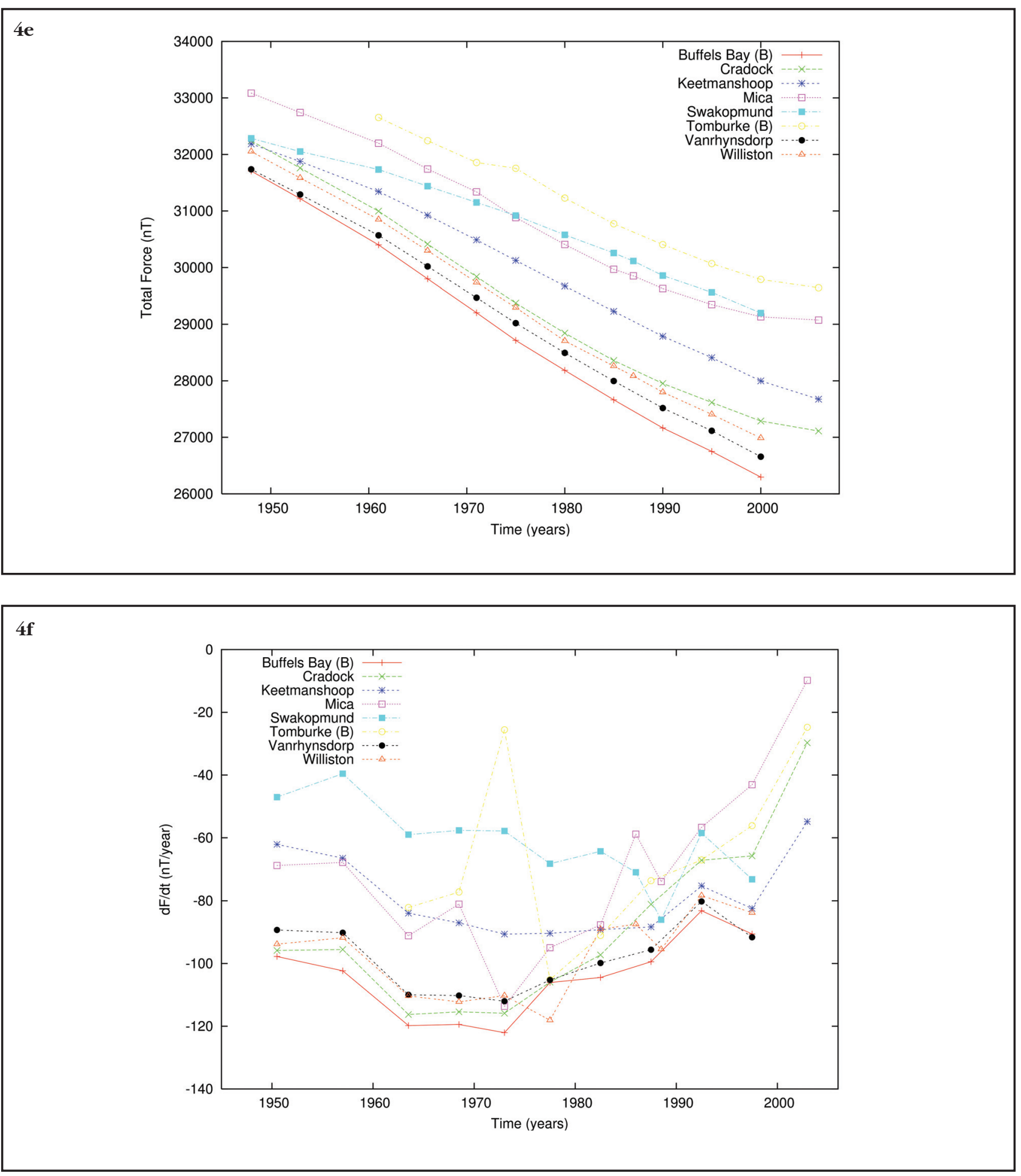

Figure 4 continued. Temporal evolution for the magnetic field components: $D$ (declination) $H$ (horizontal component) and $F$ (total field intensity) and their secular variation for eight repeat stations distributed over the southern African continent (see Figure 1 for their spatial distribution).

significantly improved by using the recent satellite vector magnetic surveys carried out by the Ørsted, CHAMP and SAC-C missions. These missions permit the study of the geographical pattern of the secular variation during each satellite's lifetime, and also allow a comparison with former data from the MAGSAT mission in 1979 to 1980 (Langlais et al., 2003). Comparisons of MAGSAT and CHAMP satellite data indicate that the relative decrease of the geomagnetic field is particularly strong in the Atlantic and American sector (Figure 2). This coincides partly with the South Atlantic Anomaly, where the geomagnetic field is significantly weaker than over the rest of the Earth at equivalent altitudes. Besides the field intensity, the orientation of the geomagnetic field in the southern African continent is also changing rapidly. To completely describe the vector field, 


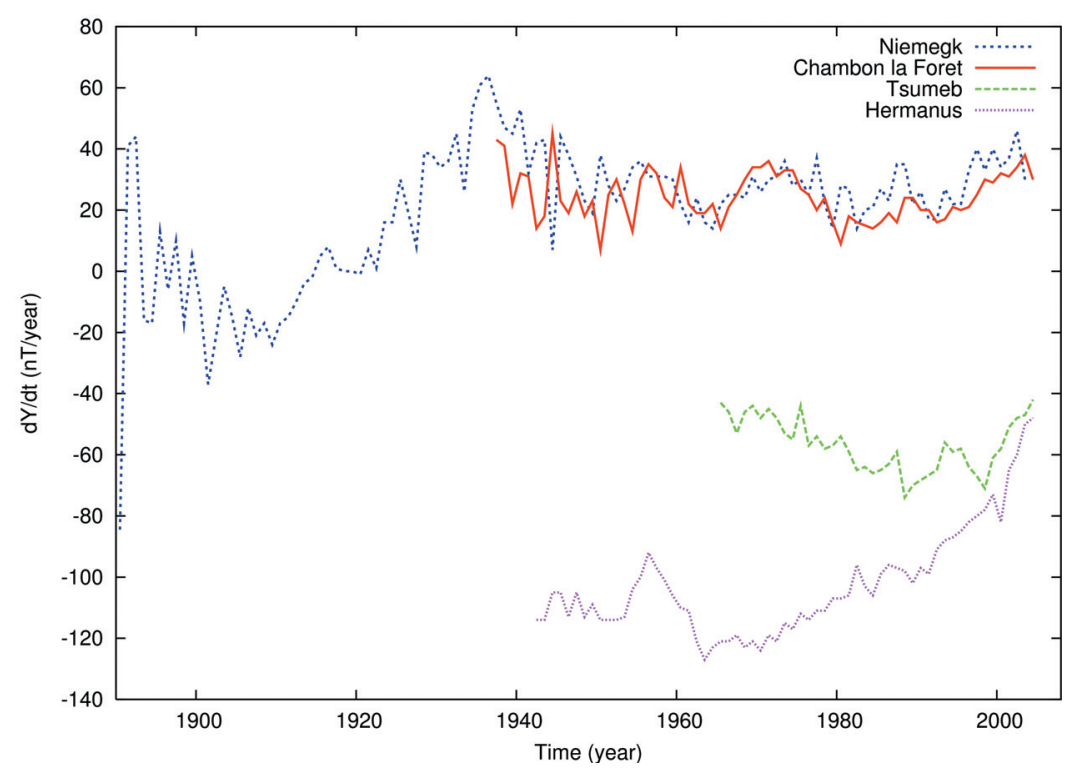

Figure 5. Secular variation plotted for the Y (magnetic east) component of two European observatories (Chambon la Forêt and Niemegk) and two southern African observatories (Hermanus and Tsumeb). Note that data from Chambon la Forêt and Niemegk observatories are used only after 1940, in order to cover the time-span with available data from Hermanus and Tsumeb.

Figure 3 shows the evolution for the three field components $(D-$ declination, $H$ - the horizontal component and $F$ - the total field intensity). In the northwest part of southern Africa the declination of the magnetic field is propagating eastward (Tsumeb) while in the south-east part it propagates westward (Hermanus and Hartebeesthoek). It is obvious that a spatial gradient over the subcontinent exists that presently increases with time. Continuous observations by scientists at the Hermanus Magnetic Observatory have documented a decrease in the magnetic field strength of about 26\% since the 1920s. When analysing the long-term evolution of the data obtained from repeat stations, a different behaviour is observed between stations situated in the

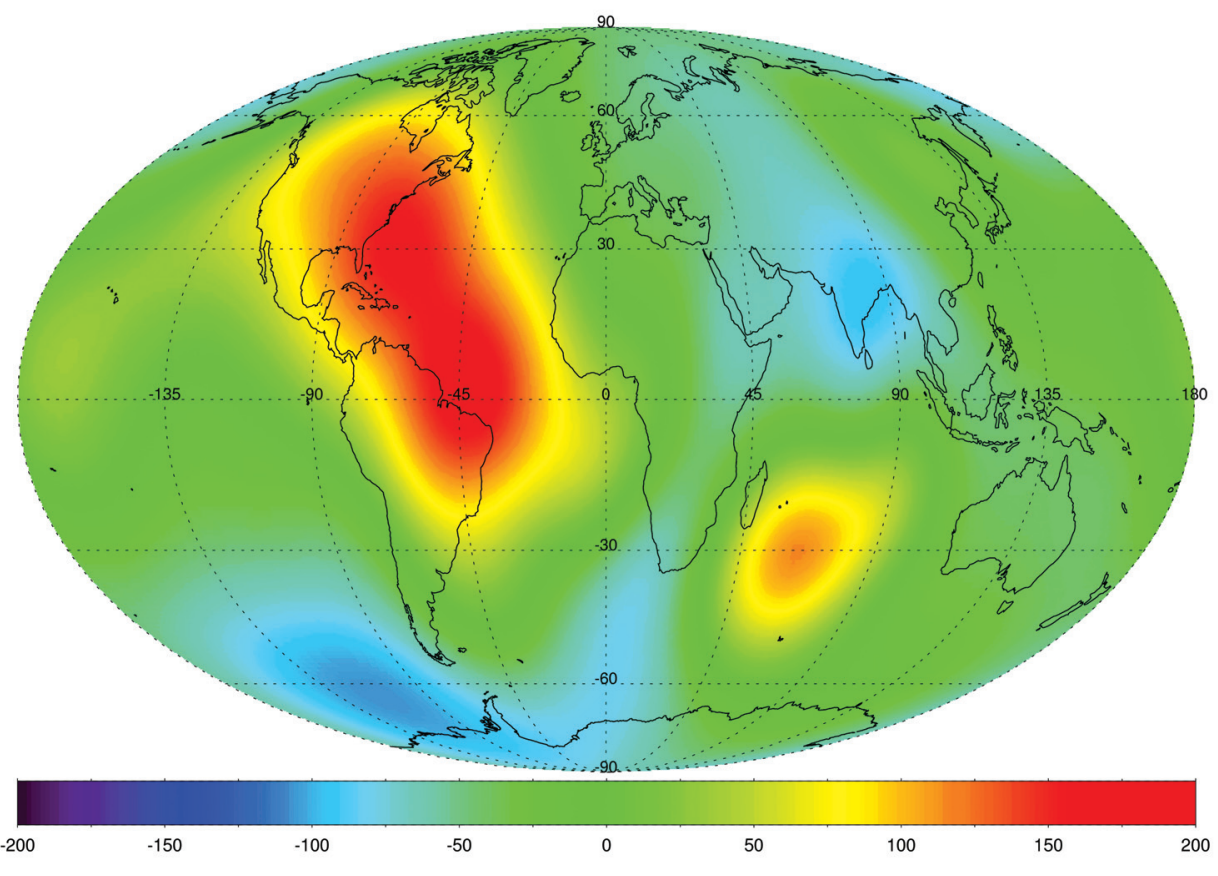

Figure 6. Map of the secular variation of the radial field at the Earth's surface computed from the CHAOS model for epoch 2002.5 and degree $\mathrm{n}=14$. Units $\mathrm{nT} / \mathrm{yr}$. 


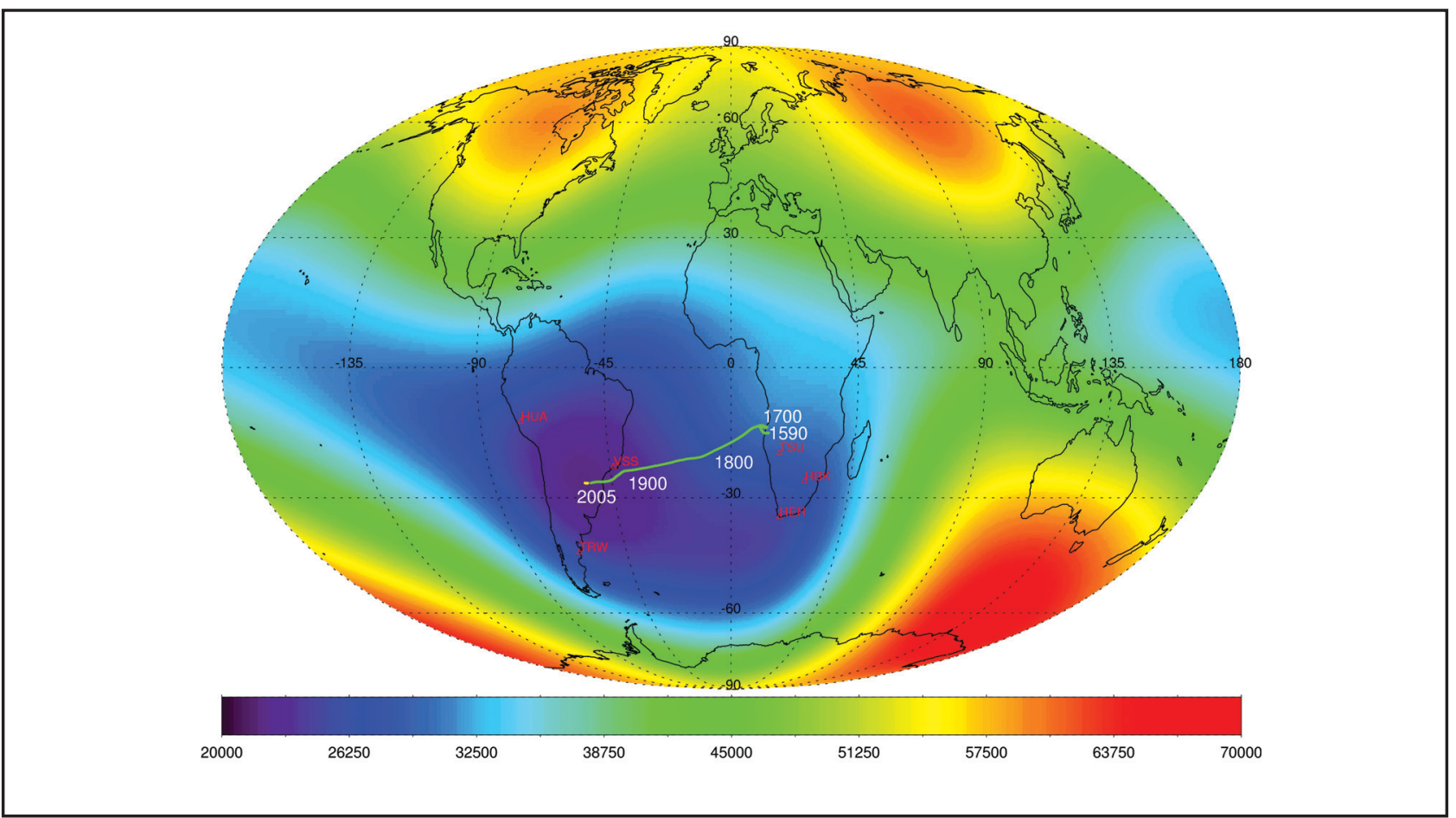

Figure 7. Map of the total field intensity for epoch 2005, computed from the CHAOS model. The South Atlantic Anomaly is well defined by its weaker field values. The track of the minimum of this anomaly over the last four centuries is shown by the green (GUFM) and yellow (CHAOS) lines with white labels indicating the approximate year. Several nearby magnetic observatories are highlighted in red (HUA Huancayo, VSS - Vassouras, TRW - Trelew, TSU - Tsumeb, HBK - Hartebeesthoek, HER - Hermanus). Units nT.

south-east, centre, and south-west parts of the continent (Figure 4).

From the examination of the geomagnetic series provided by the three southern African observatories, the intriguing observation is made that the date of change in the declination trend coincides with that of a well-documented geomagnetic jerk (Mandea et al., 2000). This simple observation, evident in Figure 3 , brings to light new questions about geomagnetic jerks and their role on small spatial scales. Moreover, considering two European observatories (Chambon-laForêt and Niemegk) separated by a comparable distance as the two southern African ones (Tsumeb and Hermanus), makes it possible to underline the different behaviour between these two regions (Figure 5). Chambon-la-Forêt and Niemegk show the same temporal changes, whereas Tsumeb and Hermanus change dramatically in declination behaviour after 1980 .

A recent model, CHAOS (Olsen et al., 2006), covering more than 6.5 years, brings important improvements in describing the secular variation from solely satellite data. Indeed, secular variation, no longer considered just linear, has its non-linear time changes described by means of splines in order to avoid unreasonable values near the limits of the time interval. This model allows us to estimate the changes in the geomagnetic field during the last few years, without any biases introduced by data quality or by various approaches in modelling. Figure 6 illustrates the secular variation of the radial field at the Earth's surface obtained from this model. The radial field is shown here, as this component and its secular variation are the ones expressed at the top of the core in order to infer outer core fluid motion.

\section{South Atlantic Anomaly}

It is in this region that the shielding effect of the magnetic field is severely reduced, thus allowing high energy particles of the hard radiation belt to penetrate deep into the upper atmosphere to altitudes below $100 \mathrm{~km}$. The region has an impact for spacecraft orbiting at several hundred $\mathrm{km}$ altitude with inclinations between $35^{\circ}$ and $60^{\circ}$, as they are exposed to several minutes of strong radiation on each orbit. The South Atlantic Anomaly (SAA) is clearly observed when the magnetic field intensity is computed from satellite measurements. Once more, the CHAOS model is used, and Figure 7 shows that the magnetic field is becoming generally weaker in this specific region. To find out how this anomaly has changed in time, we also plot in Figure 7 the location of the minimum of the magnetic field intensity in time. The values computed here are based on two models, covering various time-spans: 1590 to 1990 from the GUFM model (Jackson et al., 2000) and 1999 to 2005 from the CHAOS model (Olsen et al., 2006). The SAA minimum has moved over the last four centuries, from the southern African continent to South America, with a notable rate during the last few centuries. 


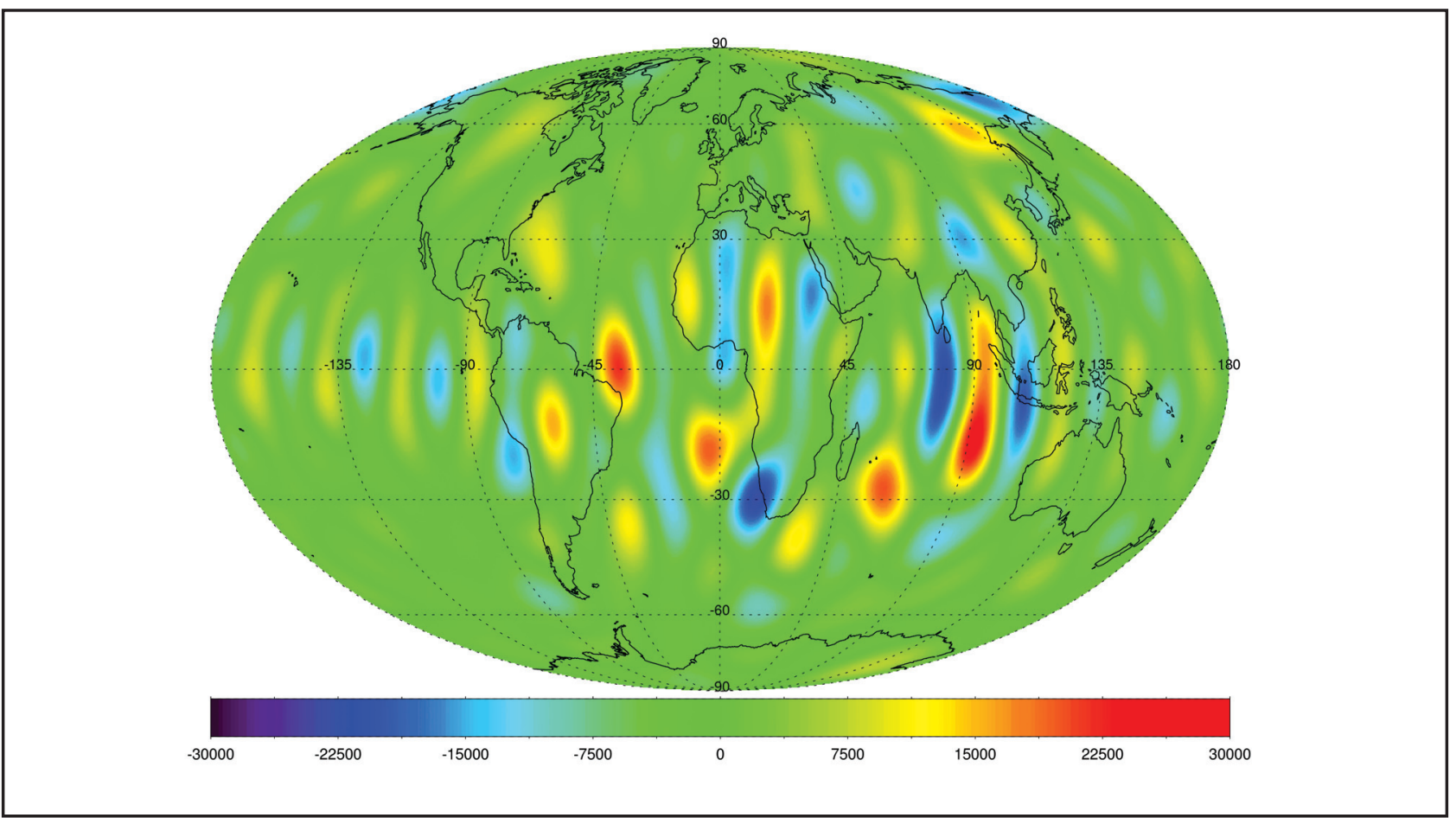

Figure 8. Map of the secular variation of the radial field at the core-mantle boundary $\left(\mathrm{R}_{\mathrm{cmb}}=3480 \mathrm{~km}\right)$ for epoch 2002.5 . The field values are computed from the CHAOS secular variation model up to degree $\mathrm{n}=14$. Units nT/yr.

\section{At the core-mantle boundary}

The robust CHAOS model resolves secular variation coefficients beyond degree 13 , which means that for the first time it is possible to infer the temporal changes of the core field to smaller scales than the field itself and to evaluate structures with short wavelengths at the coremantle boundary never before observed (Figure 8). This figure shows that the southern African continent is one of two regions of very active variations of the secular variation, where wave-like structures propagate (Dormy and Mandea, 2005). The magnetic activity within these structures directly relates to the geomagnetic jerks previously reported at the Earth's surface (Mandea et al., 2000).

Another interesting feature is linked to changes in the global magnetic flux. Considering the CM4 model (1960 to 2002) published by Sabaka et al. (2002) and a 20-year time span (to keep the same time interval as in Figure 2), the total flux for the epochs 1980 and 2000 was computed. Figure 9 shows that 20 years is enough to change the flux patterns. Globally speaking, the most evident change is the transition of the reverse patch in the Pacific Ocean to the north, becoming part of the large Northern Hemisphere patch. Under the region of interest, patches 1 and 2 have also a clear evolution in time. Patch 1 is round and its surface area increased by nearly $52 \%$ over 20 years. Patch 2, having previously coalesced from three distinct, smaller patches, is more extended and shows only a modest increase in surface area by almost 2\%. However, its morphology has changed significantly over this time and shows signs that it might split again into two segments (near $60^{\circ} \mathrm{S}$, $\left.35^{\circ} \mathrm{W}\right)$.
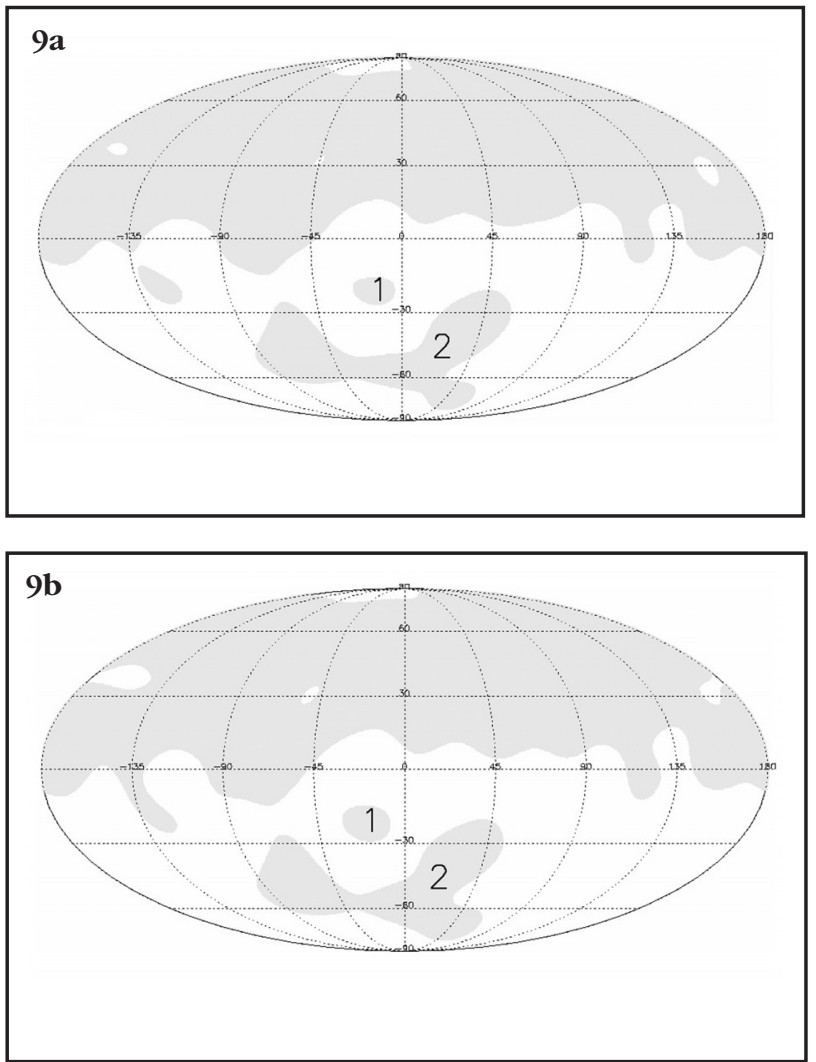

Figure 9. Maps comparing the global flux calculated from the CM4 model to degree $n=10$ for epochs 1980 (a) and 2000 (b). Note over the intervening time the reconnection of a small reverse flux patch in the Pacific with the large northern patch. Two other larger reverse flux patches are labelled and show an increase in surface area over the time interval. Patch 1 increases by nearly $52 \%$ while Patch 2 increases by almost $2 \%$. 


\section{Conclusion}

During the last few years, several new satellites (Ørsted, CHAMP, SAC-C) were launched to measure the Earth's magnetic field from space; these new data serve as an important complement to the ground-based data provided by magnetic observatory and repeat station networks. The biggest benefit of this huge new amount of magnetic field data (from ground and space) comes from the ability to get a better insight into the hidden interior of the planet and its place in the magnetic solar system.

We have taken advantage of these exceptional datasets for a detailed investigation of the SAH. This region shows a very interesting behaviour of the magnetic field and its temporal variations. An important question is how well does the secular change derived from satellite models fit the ground-based measurements in this very dynamic region? If differences are observed, how can they be explained? Are they due to imperfections in the model? Do induction anomalies in the ground adversely affect the model? These questions can only be answered when high-quality data for a few annual repeat stations campaigns becomes available during the coming years. Moreover, this region with its rapidly changing internal magnetic field is ideally suited to test the idea that rapid secular variation can induce currents in highly conductive lateral structures in the lithosphere or upper mantle. The magnetic signature caused by these confined currents is expected to change at the rate of the secular variation and not of the field itself. From the results obtained in such an investigation, it will be possible to decide whether similar studies in other parts of the world can be expected to be successful.

The Earth's magnetic field will remain under observation with the European Space Agency's forthcoming Swarm mission. Three satellites will be launched in 2010 to measure the magnetic field and its variations with unprecedented accuracy. However, a comprehensive separation and understanding of the processes contributing to the geomagnetic field is possible only by joint analysis of satellite and groundbased data, despite all the difficulties that combining such different datasets entails. Continuous space-borne and ground-based monitoring of the magnetic field aim to address such needs, and in the $\mathrm{SAH}$, as one of the most interesting and intriguing regions, such measurements should to be continued. During the next few years the COMPASS project will be extended, with the hope that for at least every two years the southern African repeat station network will be measured. Moreover, repeat stations can be installed in some nearby countries, such as Mozambique. Finally, let us stress the efforts made by GFZ Potsdam to install a new magnetic observatory at the St. Helena Island (see again Figure 1). At the time of this writing, the magnetic instruments (three-components fluxgate FGE, DI-flux Zeiss 010B with a mounted magnetometer MAG01H and two Overhauser magnetometers - GSM19 and GSM90) to be installed at the St. Helena are currently being tested in Niemegk observatory, although some administrative work remains. With these efforts we hope to support the Swarm mission data with a better distributed ground dataset.

\section{Acknowledgements}

All figures were produced with GMT (28). We would like to thank Alexander Jordan and Martin Rother for graphic support. We express our sincere thanks to Angelo De Santis and an anonymous referee for their comments that improved our paper. To Maarten de Wit and Brian Horsfield a special thanks is definitely deserved for editing this special INKABA issue. This is Inkaba ye Africa contribution number 05.

\section{References}

Dormy, E. and Mandea, M. (2005). Tracking geomagnetic impulses down to the core-mantle boundary, Earth and Planetary Science Letters, 237, 300-309.

Langlais, B., Mandea, M. and Ultré-Guèrard, P. (2003). High-resolution magnetic field modeling: application to MAGSAT and Ørsted data, Physics of Earth and Planetary Interiors, 135, 77-92.

Jackson, A., Jonkers, A.R.T. and Walker, M.R. (2000). Four centuries of geomagnetic secular variation from historical records, Philosphical Transactions of the Royal Society, London, 358, 957-990.

Korte, M., Mandea, M., Kotzé, P., Nahayo, E. and Pretorius, B. (2007a). Improved observations at the Southern African geomagnetic repeat station network, South African Journal of Geology, 110, 175-186.

Kotzé, P., Mandea, M. and Korte, M. (2007b). Modelling the Southern African geomagnetic field secular variation using ground survey data for 2005, South African Journal of Geology, 110, 187-192.

Mandea, M., Bellanger, E. and Le Mouël, J.-L. (2000). A geomagnetic jerk for the end of 20th century? Earth and Planetary Science Letters, 183, 369-373. Mandea, M. and Purucker, M. (2005). Measurements of the Earth's magnetic field from space, Surveys in Geophysics, 26, doi:10.1007/s10712-005-3857-x, 415-459.

Maus, S. and Lühr H. (2005). Signature of the quiet-time magnetospheric magnetic field and its electromagnetic induction in the rotating Earth, Geophysical Journal International, 162, 755-763, doi:101111/j.1365246.2005.02691.x.

Maus, S., Rother, M., Stolle, C., Mai, W., Choi, S., Lühr, H., Cook, D. and Roth, C. (2006). Third generation of the Potsdam Magnetic Model of the Earth (POMME), Geochemistry, Geophysics and Geosystems, 7, Q07008, doi: 10.1029/2006GC001269, 2006.

Olsen, N., Lühr, H., Sabaka, T., Mandea, M., Rother, M., Toffner-Clausen, L. and Choi, S. (2006). CHAOS - A Model of Earth's Magnetic Field derived from CHAMP, Orsted, and SAC-C magnetic satellite data, Geophysical Journal International, 165, doi:10.1111/j.1365-246X.2006.03059.x.

Sabaka, T.L., Olsen, N. and Langel, R.A. (2002). A comprehensive model of the quiet-time, near-Earth magnetic field: Phase 3, Geophysical Journal International, 151, 32-68.

Thomson, A.W.P. and Lesur, V. (2007). An improved geomagnetic data selection algorithm for global geomagnetic field modelling, Geophysical Journal International, 168, doi:10.1111/j.1365-246X.2007.03354.x.

Verbanac, G., Korte, M. and Mandea, M. (2007). On long-term trends in European geomagnetic observatory biases, Earth Planets Space, (in press).

Editorial handling: M.J. de Wit and Brian Horsfield 